\title{
Gender-Based Content of Educational Materials for the Study of Serbian Language in Lower-Stage Grades of Elementary Education
}

\author{
Vesna Trifunovic ${ }^{1} \&$ Ruzica Petrovic ${ }^{1}$ \\ ${ }^{1}$ Faculty of Pedagogical Sciences, University of Kragujevac, Jagodina, Serbia \\ Correspondence: Ruzica Petrovic, Faculty of Pedagogical Sciences, University of Kragujevac, Jagodina, Serbia. \\ E-mail: prof.ruzica@gmail.com
}

Received: December 24, 2013 Accepted: January 28, 2014 Online Published: February 19, 2014

doi:10.5539/ies.v7n3p22

URL: http://dx.doi.org/10.5539/ies.v7n3p22

\begin{abstract}
This paper presents the results of analysis of educational materials for the study of Serbian language in lower-stage grades of elementary education (intended for students from 7 through 11 years old) from gender perspective. The first part of the paper presents the process of institutionalization of gender-based education in the Republic of Serbia after the year 2000, when gender issues became highlighted as an integral part of the overall reform of education within the implementation of education for democracy and civil society. Declarative commitment to developing gender sensitivity has led to changes in the curriculum for elementary education and, presumably, changes in the selection of educational materials for different school subjects. The authors intended to determine whether educational materials for Serbian language honor the principle of gender equality in the selection of literary texts. The presence and nature of gender-based content in reading books from different publishers, for second and third grade, was determined by using the method of content analysis. The aim was to establish empirical evidence that would show the degree of gender sensitivity of analyzed educational materials and their compliance with the strategic commitment to gender mainstreaming in education.

The authors are aware of the range of this micro-level research, and the impossibility to reach general conclusions, however, in their opinion, the obtained data may shed a light on at least one part of the mosaic of the complex relationship of education, educational material and gender equality in contemporary Serbian society. The following conclusions were drawn: (a) the analyzed educational material serves the function of developing gender sensitivity; (b) the principle of gender equality is respected in selection of the material; (c) the distinguished gender characteristics go beyond the so-called traditional gender pattern.
\end{abstract}

Keywords: elementary education, gender-based content, literary text

\section{Introduction}

At the basis of the reform of education in Serbia after the year 2000, lies the democratization of education based on principles of equality and participation, which generated the educational action for promoting equality between men and women. Based on international documents, which provide standards on gender sensitivity in education (Recommendation 1281 (1995) of the Parliamentary Assembly of the Council of Europe on gender equality in education; Recommendation CM/Rec (2007) 13 of the Committee of Ministers to member states on gender mainstreaming in education and explanatory memorandum; Recommendation CM/Rec (2007) 17 of the Committee of Ministers to member states on gender equality standards and mechanisms, etc.) and national standards (Law on the Fundamentals of the Education System, 2009; Law on Elementary Schools, 2002, 2003, 2005, 2009; Law on Textbooks and Other Teaching Aids, 2009, etc.), the commitment of Serbian society to introduce education for young people that promotes gender equality is clearly evident.

In order to keep up with educational trends of the so-called contemporary European society, the educational strategy of the Republic of Serbia has put the issues of democratization and human rights in the foreground. Highlighting these issues may indirectly bring to a conclusion that in the previous (socialist) social system, gender discrimination used to exist at different levels of education. The facts, however, show that the process of democratization of education, which began in the fifties of the last century, affected almost all newly arrived generations included in compulsory elementary education. Analysis of school work achievement at the beginning of the eighties, showed that only a small number of young people was not included in elementary education (about 2-3\%), or that they left school before finishing it, and the percentage of those continuing their 
education after elementary school was about 95\% (Ratkovic, 1984; Ivanovic, 2005). At the same time, the education process conveyed the so-called system of supreme values in which equality between men and women had an important place and was in accordance with the socialist vision of social development. Therefore, emphasizing the importance of education on gender equality, nowadays, can be viewed as an attempt to preserve the continuity of educational development in the modern Serbian society.

New generations are accepting socially desirable characteristics (including those regarding gender) through the process of socialization. In its primary stage, the process of socialization takes place within the family (Parsons \& Bales, 1955), and in its secondary stage the institutionalized education and the so-called trained experts become the most important regulatory systems (Mejel, 2004; Lasch, 1996). Naturally, other factors of socialization also have strong influence when accepting gender roles, such as peer groups, media, etc. However, school has the ability to convey the complete system of ideas, values, feelings and habits in accordance with the commitments of a society, i.e. it can "create and develop a number of physical, intellectual and moral virtues in children, that the political society in general and specific surrounding ask of them" (Durkheim, 1981, p. 41). Through its overall action, elementary school may contribute to the formation of gender traits in early school-age children, and one of the ways to achieve this is to convey gender-based content through a variety of school subjects. Educational materials for the study of native language can convey socially accepted ideas about what men and women are, and "establish" how students understand gender identity. The specificity of this school subject lies in the fact that it uses literary texts that "communicate" with the students in a particular manner, making them more open to accepting the offered content. Characters featured in literary texts, that possess certain traits, can encourage students to mimic their behavior: "by imitating the model, people perform the potential behavior and thus transcend their inertness and implement the modelled behavior" (Wheldall, 1979, $\mathrm{p}$. 124). At the same time, the impact of gender-based content within the subject of native language can be viewed through the prism of social capital as a form of exploration of the way norms are passed down from generation to generation; over time the nature of socialization changes and generations involved in institutionalized education have different experiences, but the role of educational institutions remains the same, they are an important source of norms and networks that represent social capital (Coleman, 1988).

The theoretical framework for the analysis of gender-based content of educational materials for the study of Serbian language was developed based on literature that explores inequality and gender differences that are grouped into four categories: gender as a social organization of species; gender as a socially imposed division of labor; gender as a normative cultural definition of real man and real woman; gender as a set of traits that are the result of internalized cultural norms for men and women through variety of psychological mechanisms (Gayle, 1997; Fraser, 1997; Djoric, Zunic, \& Obradovic-Tosic, 2010; Zaharijevski, Gavrilovic, \& Petrusic, 2010). Gender as a set of traits that suggest gender differences is based on cultural norms that are conveyed through the process of socialization: boys and girls learn and adopt culturally determined traits as normal gender traits through socialization, i.e. psychological normalization of the so-called desirable traits is performed (Aronson, Wilson, \& Akert, 2005). This aspect of gender was used in the analysis as the basis for the recognition of gender-based content of educational materials for the study of Serbian language.

\section{Method}

In this micro-level research, three reading books for lower-stage grades of elementary education were analyzed, two reading books for second and one for third grade. The following criteria were used for the selection of reading books: the Ministry of Education approved their use; they belong to a group of most common educational materials (textbooks); their publishers cover most of the programs and classes with their publications. The reading books in question are as follows: (1) S. Marinkovic, L. Marinkovic, \& Markovic (2005). Reading Book for Second Grade of Elementary School. Belgrade: Creative Center. (2) Manojlovic \& Babunovic (2009). Reading Book for Second Grade of Elementary School. Belgrade: Eduka. (3) Milatovic (2004). Reading Book with the Basic Concepts of Language for third grade of primary school. Belgrade: Institute for Textbooks and Teaching Aids.

For the purpose of analysis, observation units were placed within the basic text (fairy tales, stories, poems). The content of textbooks was analyzed so that the relevant gender-based content was identified, listed and described through gender traits defined in the analytical framework through the fourth aspect - gender as a set of traits that represent internalized cultural norms. Observation unit used in the analysis was a semantic unit with gender-sensitive content. A word or a phrase, in which a person that functions as a subject or an object can have its gender easily identified, and is therefore, considered gender-sensitive. Characteristics of the observation unit are defined in following terms: the type of characters (their sex); age characteristics of the subject (younger age boys and girls); personal traits of the subject. The overall results of the analysis include: (a) quantitative 
representation of boys and girls in the analyzed educational material; (b) qualitative representation of boys and girls in the analyzed material from the aspect of attributing traits to boys and girls.

In the context of democratization of education, the idea of gender equality is manifested as an issue of human rights and equal concern for the interests and needs of men and women in public and private life. This equality does not imply that men and women will become the same, but is an assurance that their rights cannot depend on the perception of gender roles. Development of gender relations begins with the effect of society and culture on the process of socialization of sexes, from family through school and so on. Institutions and instruments of culture can significantly influence the formation of attitudes toward men and women, promote the system of evaluation of gender roles and contribute to the reproduction and strengthening of gender stereotypes or their degradation (Hodzic, Bijelic, \& Cesar, 2000; Djoric et al., 2010; Djuric, 1996; Roth, 1994).

Textbooks as cultural models can form the cultural experience of every child. They openly favor some experiences, while disregarding others; actively shape physical and mental "profile" of the members of a certain culture and are able to influence intra-individual and inter-individual lives of those targeted - the students. Cultural "mission" of textbooks takes place simultaneously on several levels: some follow conscious, direct, deliberate, proclaimed objectives, while others represent latent, background side effects that the authors of textbooks are usually unaware of. They provide content that is implied, which is not often perceived as a cultural message, as they are very much part of the cultural heritage and an integral part of our most important psychological instances. However, they both exercise cultural influence (Plut, 2003, p. 46). A textbook is at the same time the primary teaching aid and the basic cognitive aid of socialization, which includes the element of culturalization: a source of knowledge about the culture and an "instruction" on how to create a culture that includes the formation of the way we perceive ourselves, and our attitude towards opposite sex. A textbook can therefore convey certain culturally significant messages, stating that its overall effect on school population is limited by a number of other factors that also play a role in forming the culture. Family, media, peers, and the so-called school factors, teachers, the nature of social interaction in school, which are all a reflection of interaction in a broader social context, each in their own way affects the process of conveying cultural messages. When taking them into consideration, it is difficult to discern cause and affect relationships, however, imagination (Mills, 1964) can help restore the connection between structures of observed entities.

\section{Results and Discussion}

Analysis of the Reading book for second grade of elementary school, published by the publishing house Creative Center (2005), revealed the following: the Reading book is comprised of 64 texts; quantitative presence of male and female characters (boys and girls) is presented in Table 1.

Table 1. Number of characters based on gender

\begin{tabular}{ccccccc}
\hline $\begin{array}{c}\text { Reading book for second } \\
\text { grade } \\
\text { (Creative Center) }\end{array}$ & \multicolumn{7}{l}{ Sex/Gender } \\
\hline & \multicolumn{2}{c}{ Male } & \multicolumn{2}{l}{ Female } & \multicolumn{2}{c}{ Total } \\
\cline { 2 - 7 } & $\mathrm{F}$ & $\%$ & $\mathrm{f}$ & $\%$ & $\mathrm{f}$ & $\%$ \\
Poetry & 4 & 16.7 & 3 & 12.5 & 7 & 29.2 \\
Prose & 11 & 45.8 & 6 & 25.0 & 17 & 70.8 \\
Total & 16 & 62.5 & 9 & 37.5 & 24 & 100 \\
\hline
\end{tabular}

Data in Table 1 shows the number of featured male and female characters (boys and girls) is not balanced. There is a greater number of male than female characters, with the ratio 16 to 9 . Nearly two-thirds, more precisely $62.5 \%$ of the main characters in selected literary texts are boys; $37.5 \%$ of the main characters are girls.

Analysis of the Reading book for second grade of elementary school, published by the publishing house Eduka (2009) revealed the following: the Reading book is comprised of 42 texts; quantitative presence of male and female characters (boys and girls) is presented in Table 2. 
Table 2. Number of characters based on gender

\begin{tabular}{ccccccc}
\hline $\begin{array}{c}\text { Reading book for second } \\
\text { grade-publisher Eduka }\end{array}$ & \multicolumn{7}{c}{ Sex/Gender } \\
\hline & \multicolumn{2}{c}{ Male } & \multicolumn{2}{c}{ Female } & \multicolumn{2}{c}{ Total } \\
\cline { 2 - 7 } & $\mathrm{F}$ & $\%$ & $\mathrm{f}$ & $\%$ & $\mathrm{f}$ & $\%$ \\
Poetry & 3 & 19 & 1 & 6 & 4 & 25 \\
Prose & 8 & 50 & 4 & 25 & 12 & 75 \\
Total & 11 & 69 & 5 & 31 & 16 & 100 \\
\hline
\end{tabular}

Data in Table 2 shows the number of featured male and female characters (boys and girls) is not balanced, the imbalance is even more pronounced than in the previous case. There is a greater number of male than female characters, with the ratio 11 to 5 . More than two-thirds, more precisely $69 \%$ of the main characters in selected literary texts are boys; $31 \%$ of the main characters are girls. The reason for that can be found in a reduced number of texts published in the 2009 edition of the Reading book, a total of 42 compared to 64 literary texts in the 2005 edition.

Analysis of the Reading Book with the Basic Concepts of Language for third grade of elementary school, published by the publishing house Institute for Textbooks and Teaching Aids (2004) revealed the following: the Reading book is comprised of 51 texts (poems, stories, short stories, fables, excerpts from short stories and drama); quantitative presence of male and female characters (boys and girls) is presented in Table 3.

Table 3. Number of characters based on gender

\begin{tabular}{|c|c|c|c|c|c|c|}
\hline \multirow{3}{*}{$\begin{array}{l}\text { Reading book for third } \\
\text { grade (Institute for } \\
\text { Textbooks and Teaching } \\
\text { Aids) }\end{array}$} & \multicolumn{6}{|c|}{ sex/gender } \\
\hline & \multicolumn{2}{|c|}{ Male } & \multicolumn{2}{|c|}{ Female } & \multicolumn{2}{|c|}{ Total } \\
\hline & $\mathrm{F}$ & $\%$ & $\mathrm{f}$ & $\%$ & $\mathrm{f}$ & $\%$ \\
\hline Poetry & 2 & 13.3 & 1 & 6.7 & 3 & 20 \\
\hline Prose & 9 & 60 & 3 & 20 & 12 & 80 \\
\hline Total & 11 & 73.3 & 4 & 26.7 & 15 & 100 \\
\hline
\end{tabular}

Data in Table 3 also shows the number of featured male and female characters (boys and girls) is not balanced and shows the highest disproportionality. There is a greater number of male than female characters, with the ratio 11 to 4 . The percentage is expressed as follows: $73.3 \%$ of the main characters in selected literary texts are boys; $26.7 \%$ of the main characters are girls.

Personal traits of featured male and female characters (boys and girls) in the Reading books for second grade published by the publishing houses Creative Center (2005) and Eduka (2009), are summarized in Table 4. 
Table 4. Personal traits based on gender

\begin{tabular}{ccc}
\hline \multicolumn{3}{c}{ Reading books for second grade-publishers Creative Center and } \\
\hline Eduka & \\
\hline Traits & Male characters & Female characters \\
\hline Mischievous & 1 & 2 \\
Stupid & $/$ & 1 \\
Resourceful & 4 & 2 \\
Helpless & $/$ & 1 \\
Cranky & 2 & $/$ \\
Greedy & 1 & $/$ \\
Intelligent & 6 & 2 \\
Wise & 3 & 1 \\
Righteous & 1 & $/$ \\
Good & 1 & 2 \\
Curious & 1 & $/$ \\
Defiant & 1 & 1 \\
Timid & 1 & $/$ \\
Lazy & 1 & 1 \\
Diligent & 1 &
\end{tabular}

Data in Table 4 shows personal traits attributed to featured characters in 35 instances. Boys are more often presented as resourceful, intelligent and wise, but also as cranky. In the analyzed texts, the traits such as cranky, greedy, righteous, curious, defiant, lazy and diligent are attributed only to male characters (boys). Female characters (girls) are most commonly presented as good, intelligent, wise, resourceful and mischievous; in fewer instances they are presented as timid, helpless or stupid.

Personal traits of featured male and female characters (boys and girls) in the Reading book for third grade of elementary school, published by the publishing house Institute for Textbooks and Teaching Aids (2004), are summarized in Table 5.

Table 5. Personal traits based on gender

\begin{tabular}{|c|c|c|}
\hline \multicolumn{3}{|c|}{$\begin{array}{l}\text { Reading books for third grade-publisher Institute for Textbooks } \\
\text { and Teaching Aids }\end{array}$} \\
\hline Traits & Male characters & Female characters \\
\hline Indifferent & 1 & 1 \\
\hline Diligent & 1 & / \\
\hline Determined & 1 & / \\
\hline Empathetic & 1 & I \\
\hline Inquisitive & 5 & 2 \\
\hline Devoted & 1 & I \\
\hline Curious & 1 & / \\
\hline Intelligent & 1 & / \\
\hline Rebellious & 1 & 1 \\
\hline Advised & 1 & 1 \\
\hline Critical & / & 1 \\
\hline
\end{tabular}


Data in Table 5 shows personal traits attributed to featured characters in 19 instances. The most prominent trait of male characters (boys) is inquisitiveness; boys are presented as indifferent, diligent, determined, empathetic, dedicated, curious, intelligent and rebellious. In the analyzed texts traits such as diligent, determined, empathetic, dedicated, curious and intelligent are attributed only to the male characters (boys). The most prominent trait of female characters (girls) is, as well as in males - inquisitiveness. The girls are presented as indifferent, rebellious, advised and critical. Interestingly, traits such as advised and critical are attributed only to girls.

Data obtained by analyzing the content of the above mentioned reading books can be compared with data obtained in a much broader study "Education on Gender Equality: Analysis of Educational Materials for Civic Education" (Djoric et al., 2010). Moreover, in the part concerning quantitative representation of male and female characters in the manuals for Civic Education and their attributed traits. The authors of this study reported the following findings: (a) an effort to balance the number of male and female characters in the manuals for Civic Education is evident; (b) an attempt to attribute similar traits to boys and girls is also evident, however, stereotypical description of girls as "manipulative and passive cry-babies", and boys as "enterprising, inquisitive, courageous, arrogant and irresponsible" prevails. The authors of the study conclude that: “... textbooks for young elementary-school children greatly change the stereotypical patriarchal understanding of the world and introduce principles of gender equality in many areas of educational material. Of course, in order for educational material to reflect the set objective of the school subject, it is necessary to make an extra effort to dismantle gender stereotypes of family roles through which students learn and shape their behavior. Extra effort needs to be invested into breaking stereotypes about personal traits of featured male and female characters (Djoric et al., 2010, p. 51).

Similar study, "Education on Gender Equality: Analysis of Educational Materials in Elementary and Secondary Education" (Zaharijevski et al., 2010), the focus of which was gender perspective in programs and textbooks for school subjects The World Around Us, Nature and Society, Biology, Geography, Sociology, Constitution and Rights of Citizens, provides some possibility of comparison. Only findings concerning the quantitative representation of male and female characters in the analyzed material shall be listed, as well as findings related to the presence of prominent figures instead of character traits. The authors estimate that "the process of introduction of gender perspective in programs and educational materials is not even nearly finalized" (Zaharijevski et al., 2010, p. 112), but some progress is evident in books for young school-age children. They point out the following: (a) quantitative presence of male and female characters is unbalanced, i.e. twice as many male characters is presented; (b) particularly unbalanced is the number of prominent figures presented in textbooks, which are predominantly male. The authors propose introducing "gender mainstreaming" in the curriculum.

\section{Conclusion}

Gender relations are specific to each society, culture and historical era, but the mechanism of their formation is always the same-they form actively and reproduce through the process of growing up and socialization. Through institutionalized education, where one phase of socialization occurs, new generations are conveyed social values and norms, which enable them to integrate in the social community.

The concept of gender equality is recognized and promoted in legislation governing various dimensions of life in contemporary Serbian society, including education. Gender perspective is integrated in the curriculum for elementary schools, as well as in other institutional levels of education, as a natural consequence of the society's commitment to develop gender equality. Gender-based content can be identified in a number of educational materials for different school subjects. Yet only the complex and continuous analysis of the overall school activity, particularly the analysis of gender constructs within different school subjects, may indicate a correlation between gender-based content and acceptance of the concept of gender equality by the young school-age population.

Gender-based content of educational materials for the study of Serbian language can be an important factor in introducing young school-age children to the "social ideal" of the relationship between a man and a woman. However, its real impact cannot be precisely "measured". Overcoming gender stereotypes by "relieving" books of traditional gender-based content, which always includes some form of discrimination, is a way to encourage new generations to accept the ideas of gender equality. However, textbooks and other educational materials, even when they include texts of exceptional literary merit, are not sufficient to shape the desired relationship between genders. It is essential that a wide range of factors, from a broader social context, promotes the idea of equality (local community, family, different organizations, media) and accomplishes a change of "nature" of intra-school factors (overall school atmosphere, social relationships between all participants in education, teacher 
competence) in order for school-age children to develop sensitivity for issues of gender identity.

The analysis of educational materials for the study of Serbian language in lower-stage grades of elementary education showed the presence of gender-based content, with the quantitatively more pronounced presence of male characters. At the same time, the presented traits of male and female characters are such that they do not coincide with the traditional division between "male" and "female" traits. The characters of boys and girls possess the same traits, for example intelligent, wise and resourceful; on the other hand, atypical traits are attributed to some characters - boys are timid and empathetic, and girls are rebellious and advised. The presence of gender-based content and its character in the analyzed reading books shows that, in the dimension of gender relations, socially determined relations between men and women are conveyed to school population: they are constantly being shaped and the right "measure" of relation is still not established.

\section{References}

Aronson, E., Wilson, D. T., \& Akert, M. R. (2005). Social Psychology. Zagreb: Mate.

Coleman, J. S. (1988). Social Capital in the Creation of Human Capital. American Journal of Sociology, 94(Supplement), S95-S120. Retrieved from http://www.jstor.org/stable/2780243

Djoric, G., Zunic, N., \& Obradovic-Tosic, T. (2010). Education on Gender Equality: Analysis of Educational Materials for Civic Education. UNDP.

Djuric, D. (1996). Social Psychology of Education. Sombor: Teacher's College.

Durkheim, E. (1981). Education and Sociology. Belgrade: Institute for Textbooks and Teaching Aids.

Fraser, N. (1997). Structuralism or Pragmatics? On Discourse Theory and Feminist Politics. In L. Nicholson (Ed.), The Second Wave: A Reader in Feminist Theory (pp. 379-395). New York and London: Routledge.

Gayle, R. (1997). The Traffic in Women: Notes on the "Political Economy" of Sex. In L. Nicholson (Ed.), The Second Wave: A Reader in Feminist Theory (pp. 27-62). New York and London: Routledge.

Hodzic, A., Bijelic, N., \& Cesar, S. (2000). Sex and Gender under the Magnifying Glass. Zagreb: CESI.

Ivanovic, S. (2005). Sociology of Education. Jagodina: Teacher's College.

Lasch, C. (1986). The Culture of Narcissism. Zagreb: Naprijed.

Manojlovic, M., \& Babunovic, S. (2009). Reading Book for Second Grade of Elementary School. Belgrade: Eduka.

Marinkovic, S., Marinkovic L., \& Markovic, S. (2005). Reading Book for Second Grade of Elementary School. Belgrade: Creative Center.

Mejel, B. (2004). Children at Work in Family and School. In S. Tomanovic (Ed.), Sociology of Childhood (pp. 227-242). Belgrade: Institute for Textbooks and Teaching Aids.

Milatovic, V. (2004). Reading Book with the Basic Concepts of Language for Third Grade of Elementary School. Belgrade: Institute for Textbooks and Teaching Aids.

Mills, W. (1964). Sociological Imagination. Belgrade: Modern School.

Parsons, T., \& Bales, R. (1955). Family, Interaction and Socialization Process. N.Y.: Free Press.

Plut, D. (2003). Textbooks as Cultural Support System. Belgrade: Institute for Textbooks and Teaching Aids, Institute of Psychology.

Ratkovic, M. (1984). Development and Contradictions of Education. Zagreb: School Newspaper.

Rot, N. (1994). Fundamentals of Social Psychology. Belgrade: Institute for Textbooks and Teaching Aids.

Recommendation 1281. (1995). Of the Parliamentary Assembly of the Council of Europe on gender equality in education. Retrieved December 15, 2013, from https://www.assembly.coe.int./mainf.asp?Link=/documents/adoptedtext/ta95/erec1281.htm

Recommendation CM/Rec. (2007). 13 of the Committee of Ministers to member states on gender mainstreaming in education and explanatory memorandum. Retrieved December 15, 2013, from https://wcd.coe.int./ViewDoc.jsp?id=1194631\&Site=CM

Recommendation CM/Rec. (2007). 17 of the Committee of Ministers to member states on gender equality standards and mechanisms. Retrieved December 15, 2013, from https://wcd.coe.int/ViewDoc.jsp?id=1215219\&Site=CM 
Zaharijevski, S. D., Gavrilovic, D., \& Petrusic, D. (2010). Education on Gender Equality: Analysis of Educational Materials for Elementary and Secondary Education. UNDP.

Law on the Fundamentals of the Education System. (2009). Official Gazette of RS, no. 72/2009. Beograd: Official Gazette.

Law on Elementary Schools. (2009). Official Gazette of RS, no. 72/2009. Beograd: Official Gazette.

Law on Textbooks and Other Teaching Aids. (2009). Official Gazette of RS, no. 72/2009. Beograd: Official Gazette.

Wheldall, K. (1979). Social behavior. Belgrade: Nolit.

\section{Copyrights}

Copyright for this article is retained by the author(s), with first publication rights granted to the journal.

This is an open-access article distributed under the terms and conditions of the Creative Commons Attribution license (http://creativecommons.org/licenses/by/3.0/). 